\title{
Modelling for Gender Discrimination at Workplace in India
}

\author{
Taskeen Zaidi \\ Computer Science and Engineering Department, SRMU University, India
}

Corresponding author: Taskeen Zaidi, Assistant Professor, Computer Science and Engineering Department, SRMU University, India, Tel: 009452372550; E-mail: taskeenzaidi867@gmail.com

Received: Jan 11, 2016; Accepted: Jan 27, 2016; Published: Jan 31, 2016

Copyright: (C) 2016 Zaidi T. This is an open-access article distributed under the terms of the Creative Commons Attribution License, which permits unrestricted use, distribution, and reproduction in any medium, provided the original author and source are credited.

\section{Letter to the Editor}

Many women at workplace are victims of aggression and harassment and they are experience to psychological problems including depression, anger and drug intake. The purpose of this research work is to study dimensions and correlates of psychological disturbance that women experience as a result of sexual harassment at the work place and psychological reach as like depression, anxiety, denial, anger, fear, frustration, irritation, embarrassment, low self-esteem, guilt and isolation. It has found that the women who are harassed and teased by males feel very uncomfortable. Even due to insecurity and fear women stop travelling at night and visiting vulnerable places to avoid unwanted situation The women get discriminated at workplace by delaying their promotion as boss makes their image negative and give there negative feedback, so it is concluded that women get late promotion as compared to male co-workers. Victims of gender discrimination lose motivation and due to this they are not performing their job well. Destructiveness may manifest itself as physical violence against others, destruction of property or propagation of malicious rumours about people in the company and the company itself.

The discrimination factors are in terms of salary provided to the working women as compared to male employees as in India women are tagged as housewife type material and offered lower salaries, as men are considered more hardworking and talented than women. In this study many women's replied that they step out of their houses in difficult times to support their families and employers take advantage of the situation by offering lower wage to them irrespective of their qualifications or qualities they are forced to accept low. Bosses and senior employers many times demand sexual favours to save their job and position they try to molest and blackmail them. Bullying employees and delegating office work, which might be, not cover the specialization of the concerned employee to. In many cases males easily get promotion irrespective of the fact they are much deserving and hardworking than male employees. There are lots of cases when any female ignored boss then due to male ego they got at workplace tortured by their boss by other ways. At Promotion are generally offered to the male employees as they are expected to be more responsible and talented of handling the job which might be a debatable question as nowadays women are better off as compared to the men at top level of organization. you think?

In this study university students indicate that female undergraduate and graduate students who experience sexual harassment change career plans, change majors, and drop courses to avoid unwanted situations, exhibiting what might be considered job withdrawal from the job of "student" harassment experiences negatively affect satisfaction with life and psychological well-being and lead to symptoms of posttraumatic stress (e.g., heart pounding or racing or having thoughts or images of a frightening nature). We hypothesize that women who experience harassment in the workplace may exhibit similarly negative psychological effects as other victims of trauma, given that harassment is often unexpected and women's beliefs about a supportive and non-hostile work environment may be threatened. For classification of data, a sample size of 500 women is considered for Gender discrimination after forming a questionnaire and four dependent classes are taken under consideration which formulate that class A shows that women feel uncomfortable; the composite reliability is computed as 0.819 which is more than 0.70 . The composite reliability of class $A$ show that high degree of uncomfortable occurs in the group of women when it is linked to class $D$ then composite reliability increases i.e. 0.814 and it is again more than 0.70 which is acceptable. 